\title{
Bradykinin induced dilatation of human epicardial and resistance coronary arteries in vivo: effect of inhibition of nitric oxide synthesis
}

\author{
Masaya Kato, Nobuo Shiode, Togo Yamagata, Hideo Matsuura, Goro Kajiyama
}

\begin{abstract}
Objective-To clarify whether endothelium derived nitric oxide contributes to exogenous bradykinin induced dilatation of human epicardial and resistance coronary arteries in vivo.

Design-Quantitative coronary angiography and Doppler flow velocity measurements were used to determine the effects of the nitric oxide synthesis inhibitor, $\mathbf{N}^{\mathrm{G}}$-monomethyl-L-arginine (L-NMMA), on bradykinin induced dilatation of the epicardial and resistance coronary arteries.

Setting-Hiroshima University Hospital. Patients-20 patients (16 men and four women, mean (SD) age 56 (9) years) with angiographically normal smooth epicardial coronary arteries.

Interventions-Serial infusions of bradykinin $(0.5,1.5$, and $2.5 \mu \mathrm{g} / \mathrm{min})$ were given into the left coronary ostium before and after L-NMMA infusion (60 $\mu \mathrm{mol} / \mathrm{min})$.

Main outcome measures-Epicardial coronary diameter, coronary blood flow, and coronary vascular resistance.

Results-Bradykinin-induced epicardial coronary vasodilatation after L-NMMA (dilatation by $2.5 \mu \mathrm{g} / \mathrm{min}, 3.8(1.4) \%$ in the proximal and $5.9(1.8) \%$ in the distal segments, mean (SEM)) was less (p<0.001, respectively) than before L-NMMA (11.7(2.5)\% and 15.1(2.0)\%, respectively). In contrast, L-NMMA did not affect the bradykinin induced increase in coronary blood flow and decrease in coronary vascular resistance.

Conclusions-Endothelium derived nitric oxide contributes to bradykinin induced dilatation of epicardial coronary arteries, but may be less important in coronary resistance vasodilatation.

(Heart 1997;78:493-498)
\end{abstract}

The First Department of Internal Medicine, Hiroshima University School of Medicine, Hiroshima, Japan

Correspondence to: Dr Kato, The First Department of Internal Medicine, Hiroshima University School of Medicine, 1-2-3 Kasumi, Minami-ku, Hiroshima 734, Japan.email:mas@mcai. med.hiroshima-u.ac.jp

Accepted for publication 2 July 1997 which is synthesised by the action of nitric oxide synthase on L-arginine, prostacyclin, ${ }^{56} \mathrm{a}$ product of cyclooxygenase mediated arachidonic acid metabolism, and endothelium derived hyperpolarising factor (EDHF).$^{7-10}$ Nitric oxide is believed to be EDRF, or a closely related compound. ${ }^{11-13}$

Bradykinin is a potent vasodilator that acts through endothelial B2 kinin receptors to stimulate the release of endothelium derived nitric oxide, prostacyclin, ${ }^{14}$ and $\mathrm{EDHF}^{7}$ and has been shown to induce endothelium dependent relaxation of human forearm ${ }^{15} 16$ and coronary arteries ${ }^{17} 18$ in vivo. However, it is uncertain which endothelium dependent vasoactive agent mediates bradykinin induced human coronary vasodilatation in vivo.

We carried out this study to clarify whether endothelium derived nitric oxide contributes to human epicardial and resistance coronary vasodilatation induced by exogenous bradyki$\operatorname{nin}$ in vivo. $\mathrm{N}^{\mathrm{G}}$-monomethyl-L-arginine (LNMMA), an analogue of L-arginine that specifically inhibits nitric oxide synthase, ${ }^{19}$ was used to inhibit the production of nitric oxide, and its effect on the vasodilator response of the coronary vasculature to bradykinin was studied.

\section{Methods}

STUDY POPULATION

We studied 20 patients (16 men and four women; mean (SD) age 56 (9) years, range 32 to 69) undergoing coronary angiography for diagnosis of a chest pain syndrome. Each patient's chest pain was atypical for effort angina. All patients had angiographically normal smooth epicardial coronary arteries, normal left ventricular function (contrast ventriculographic ejection fraction $\geqslant 50 \%$ ) and normal coronary flow reserve. Patients with a previous history of myocardial infarction, cardiomyopathy, valvar heart disease, or heart failure were excluded. Patients with coronary spastic angina who showed angiographically documented coronary spasm ( $>50 \%$ luminal narrowing) after intracoronary injection of acetylcholine were also excluded. Four patients had hypertension but no echocardiographic evidence of left ventricular hypertrophy. Hypercholesterolaemia (total serum cholesterol $>240 \mathrm{mg} / \mathrm{dl}$ ) was present in four patients, but their total serum cholesterol values were not above $270 \mathrm{mg} / \mathrm{dl}$ when not on antihypercholesterolaemic drug treatment. Two patients had well controlled diabetes mellitus, one treated with diet only and the other with oral gliclazide, 
$20 \mathrm{mg}$ /day. Four patients were current smokers (> 10 cigarettes/day), but were instructed not to smoke for at least one week before the study.

Written informed consent was obtained from each patient before the study, and the protocol was approved by the human investigation ethics committee of Hiroshima University.

STUDY PROTOCOL

Antianginal and antihypertensive drugs, including an angiotensin converting enzyme inhibitor, were discontinued at least 48 hours before the study. The diabetic patient on gliclazide discontinued the drug 24 hours before the study. Patients were brought to the catheterisation laboratory in a fasting state after premedication with intramuscular hydroxyzine $(25 \mathrm{mg})$ and promethazine hydrochloride $(25 \mathrm{mg})$. Diagnostic catheterisation was performed through a standard percutaneous femoral approach, and 10000 units of heparin were given intravenously just before the procedure. After completion of diagnostic coronary angiography, a $6 \mathrm{~F}$ guide catheter was introduced into the left main coronary artery and the coronary blood flow velocity was measured with an 0.014 inch wire equipped with a Doppler crystal at its tip (Flowire, Cardiometrics, Mountain View, California, USA). ${ }^{20}{ }^{21}$ The Doppler flow wire was advanced into the left anterior descending coronary artery in 19 patients and into the circumflex coronary artery in one, because of a small left anterior descending coronary artery. The wire tip was carefully positioned in a straight segment of the vessel to produce an adequate flow velocity signal. The vessel, within $1 \mathrm{~cm}$ of the tip, could be imaged without overlap from other vessels to allow for quantitative measurements of the coronary artery calibre.

After baseline control conditions had been established, bradykinin was infused at rates of $0.5,1.5$, and $2.5 \mu \mathrm{g} / \mathrm{min}$ for two minutes. These doses were determined with reference to the doses used for dilating human forearm vessels. ${ }^{15}{ }^{16}$ Adenosine was then infused at a rate of $100 \mu \mathrm{g} / \mathrm{min}$ for two minutes to evaluate the coronary flow reserve. After a five minute interval, L-NMMA was infused into the left coronary artery at a rate of $60 \mu \mathrm{mol} / \mathrm{min}$ for three minutes. After control conditions had been re-established, serial infusions of bradyki$\operatorname{nin}(0.5,1.5$, and $2.5 \mu \mathrm{g} / \mathrm{min})$ were given again. Finally, an intracoronary infusion of glyceryl trinitrate was given at a rate of $200 \mu \mathrm{g} / \mathrm{min}$ for one minute. All drugs were infused directly into the left main coronary artery through the catheter at an infusion rate of $1 \mathrm{ml} / \mathrm{min}$.

Coronary angiography was performed under control conditions and just after the end of each period of drug administration. The coronary blood flow velocity was monitored continuously and recorded on a $12 \mathrm{MHz}$ pulsed Doppler velocimeter (FloMap, Cardiometrics). Arterial pressure (at the distal end of the catheter), heart rate, and cardiac rhythms (from a 12 lead electrocardiogram) were also monitored continuously and recorded on a multichannel recorder (Nihonkoden Polygraph
System, Nihonkoden, Tokyo, Japan). We waited at least five minutes after each drug infusion to obtain stable values of blood flow velocity and coronary diameter. Steady state values were used for analysis.

\section{QUANTITATIVE CORONARY ANGIOGRAPHY}

The method of quantitative coronary angiography was described previously. ${ }^{22}$ After selecting the view that allowed the best visualisation of the left coronary artery, coronary cineangiograms were recorded on $35 \mathrm{~mm}$ cinefilm (30 frames per second) using a cineangiographic system (Siemens, Munich, Germany). Nonionic contrast medium, iomeprol (Iomeron 350, Eisai Pharmaceutical Co, Tokyo, Japan), was injected into the left coronary artery at the rate of 5 to $10 \mathrm{ml} / \mathrm{s}$ to a total of 7 to $10 \mathrm{ml}$. A power injector (Medrad, Pittsburgh, Pennsylvania, USA) was used to optimise the quality and reproducibility of the opacification. Nineteen left anterior descending coronary arteries and one circumflex coronary artery were studied.

The arterial diameters were measured blindly, without knowledge of the clinical characteristics of the patients. An end diastolic frame was selected on the cineprojector, and the arterial segments being studied were scanned with a videocamera. Images were digitised and analysed with a videodensitometric analysis system (Cardio-500, Kontron Instruments, Munich, Germany). Automated counter detection was performed by a geometric edge differentiation technique. ${ }^{22} 23$ Measured segments were nearly straight and about $5 \mathrm{~mm}$ long. A $6 \mathrm{~F}$ Judkins catheter was used for calibration. The average value of triplicate measurements in luminal diameter were used for analysis. To establish the reproducibility of the method, the diameter of each coronary segment was measured in 20 successive frames by two investigators. An excellent correlation between the first and second measurement (intraobserver variability) was noted in each segment $(\mathrm{Y}=1.02 \mathrm{X}-0.05$, $r=0.99, \mathrm{p}<0.001$ in the proximal; and $\mathrm{Y}=0.98 \mathrm{X}+0.04, r=0.99, \mathrm{p}<0.001$ in the distal segments, respectively). Analysis of interobserver variability in the measurement of each segment also showed high reproducibility $(r=0.99, \mathrm{p}<0.001$, respectively).

ESTIMATION OF CORONARY BLOOD FLOW AND CORONARY VASCULAR RESISTANCE

Coronary blood flow was calculated as the product of the coronary blood flow velocity and diameter using the following formula: $\pi \times$ average peak velocity $\times 0.125 \times$ diameter $^{2}$. Coronary vascular resistance was calculated as the mean arterial pressure divided by coronary blood flow. For calculating flow, the internal diameter of the vessel at the location of the sampling ( 2 to $3 \mathrm{~mm}$ distal to the wire tip) was measured by the method described above.

PREPARATION OF DRUGS

Bradykinin (Sigma, St Louis, Missouri, USA), adenosine (Sigma), L-NMMA (Sigma), and glyceryl trinitrate (Nihonkayaku Corporation, 
Table 1 Haemodynamic variables

\begin{tabular}{|c|c|c|c|c|c|c|}
\hline & \multirow[b]{2}{*}{ Control } & \multicolumn{3}{|l|}{ Bradykinin } & \multirow{2}{*}{$\begin{array}{l}\text { Adenosine } \\
100 \mu \mathrm{g} / \mathrm{min}\end{array}$} & \multirow{2}{*}{$\begin{array}{l}\text { Glyceryl trinitrate } \\
200 \mu \mathrm{g} / \mathrm{min}\end{array}$} \\
\hline & & $0.5 \mu \mathrm{g} / \mathrm{min}$ & $1.5 \mu \mathrm{g} / \mathrm{min}$ & $2.5 \mu \mathrm{g} / \mathrm{min}$ & & \\
\hline \multicolumn{7}{|l|}{ Before L-NMMA infusion } \\
\hline Mean AP $(\mathrm{mm} \mathrm{Hg})$ & $106(3)$ & $105(2)$ & $104(3)^{\star}$ & $103(2)^{\star \star}$ & $104(3)$ & \\
\hline HR (beats/min) & $64(3)$ & $65(3)$ & $65(3)$ & $66(3)$ & $64(2)$ & \\
\hline $\mathrm{RPP}(\mathrm{mm} \mathrm{Hg} \times$ beats $/ \mathrm{min})$ & $9428(493)$ & $9577(499)$ & $9315(505)$ & $9401(508)$ & $9096(436)$ & \\
\hline \multicolumn{7}{|l|}{ After L-NMMA infusion } \\
\hline Mean AP (mm Hg) & $108(3)$ & $108(3)$ & $106(3)$ & $105(3)^{\star}$ & & $96(3)^{\star \star}$ \\
\hline HR (beats $/ \mathrm{min}$ ) & $63(2)$ & $62(3)$ & $63(3)$ & $64(3)$ & & $73(3)^{\star \star}$ \\
\hline $\mathrm{RPP}(\mathrm{mm} \mathrm{Hg} \times$ beats $/ \mathrm{min})$ & $9275(529)$ & $9351(604)$ & $9354(609)$ & $9304(595)$ & & $9056(529)$ \\
\hline
\end{tabular}

Values are mean (SEM).

${ }^{\star} \mathrm{p}<0.05,{ }^{\star \star} \mathrm{p}<0.01 v$ control.

$\mathrm{AP}$, arterial pressure; HR, heart rate; L-NMMA, $\mathrm{N}^{\mathrm{G}}$-monomethyl-L-arginine; RPP, rate-pressure product.

Tokyo, Japan) were dissolved in physiological saline at appropriate concentrations, respectively. Bradykinin, adenosine, and L-NMMA were sterilised in the Department of Pharmacy of Hiroshima University Hospital. Each drug infusion was performed with an infusion pump (CFV 3000, Nihonkoden, Japan) at a rate of $1 \mathrm{ml} / \mathrm{min}$.

\section{STATISTICAL ANALYSIS}

All data are expressed as the mean (SEM). Serial changes in haemodynamic variables, epicardial coronary diameter, coronary blood flow, and coronary vascular resistance in response to bradykinin were compared by one way analysis of variance (ANOVA). Serial percent changes in the epicardial coronary diameter, coronary blood flow, and coronary vascular resistance before and after the administration of L-NMMA were compared by two way ANOVA. Paired data were compared using the Student's $t$ test as appropriate. All $\mathrm{p}$ values are two tailed, and a value $<0.05$ considered significant.

\section{Results}

HAEMODYNAMIC VARIABLES

The control mean arterial pressure, heart rate, and rate-pressure product after L-NMMA infusion were similar to those before L-NMMA infusion, and the intracoronary administration of adenosine did not alter any of these variables. Bradykinin at graded doses decreased the mean arterial pressure before and after L-NMMA infusion $(\mathrm{p}<0.01$ and $\mathrm{p}<0.05$, respectively). Glyceryl trinitrate increased the heart rate $(\mathrm{p}<0.001)$ but decreased mean arterial pressure $(p<0.001)$ compared with control values (table 1 ).

EFFECT OF L-NMMA ON THE EPICARDIAL AND RESISTANCE CORONARY VASCULAR TONE

L-NMMA reduced the epicardial coronary diameter from $3.08(0.13)$ to $2.98(0.13) \mathrm{mm}$ in proximal segments $(\mathrm{p}<0.05)$, and from $1.41(0.04)$ to $1.32(0.05) \mathrm{mm}$ in distal coronary segments $(p<0.001)$ under control conditions (fig 1). L-NMMA also reduced the coronary blood flow from 32 (3) to $24(2) \mathrm{ml} /$ $\min (\mathrm{p}<0.001)$ and increased the coronary vascular resistance from $4.2(0.6)$ to $5.8(0.8) \mathrm{mm} \mathrm{Hg} \cdot \mathrm{ml}^{-1} \cdot \mathrm{min}(\mathrm{p}<0.001)$ under control conditions (fig 2 ).
EFFECT OF L-NMMA ON BRADYKININ INDUCED DILATATION OF EPICARDIAL CORONARY ARTERIES Bradykinin induced epicardial coronary vasodilatation in a dose dependent manner before L-NMMA infusion. Bradykinin at doses of $0.5,1.5$, and $2.5 \mu \mathrm{g} / \mathrm{min}$ dilated coronary diameters from $3.08(0.13) \mathrm{mm}$ to $3.26(0.14), 3.37(0.14)$, and $3.42(0.15) \mathrm{mm}$ in proximal segments $(\mathrm{p}<0.001)$, and from $1.41(0.04) \mathrm{mm}$ to 1.50 (0.05), 1.55 (0.05), and $1.61(0.05) \mathrm{mm}$ in distal segments $(\mathrm{p}<0.001)$. Although bradykinin induced vasodilatation was observed even after L-NMMA infusion in the proximal $(\mathrm{p}<0.01)$ and distal segments $(p<0.001)$, the percentage changes in epicardial coronary diameters were less than before L-NMMA infusion in the proximal $(p<0.001)$ and distal segments $(\mathrm{p}<0.001)$ (fig 3).

EFFECT OF L-NMMA ON BRADYKININ INDUCED DILATATION OF RESISTANCE CORONARY VESSELS Bradykinin increased coronary blood flow in a dose dependent manner from 32 (3) $\mathrm{ml} / \mathrm{min}$ to 48 (4), $62(6)$, and $71(7) \mathrm{ml} / \mathrm{min}(\mathrm{p}<0.001)$. The coronary vascular resistance was progressively reduced with administrations of bradykinin from $4.2(0.6) \mathrm{mm} \mathrm{Hg} \cdot \mathrm{ml}^{-1} \cdot \mathrm{min}$ to $2.7(0.4), 2.2(0.4)$, and $1.8(0.3) \mathrm{mm} \mathrm{Hg}^{-} \mathrm{ml}^{-}$ $1 . \min (\mathrm{p}<0.001)$. After L-NMMA infusion, bradykinin also progressively increased the coronary blood flow $(p<0.001)$, and reduced the coronary vascular resistance $(p<0.001)$. Additionally, the percentage changes in coronary blood flow after L-NMMA infusion were similar to those before L-NMMA infusion, as were the changes in coronary vascular resistance before and after L-NMMA infusion (fig 4). Even in seven patients without coronary risk factors, the bradykinin induced increase in coronary blood flow after L-NMMA infusion $(46(8) \%, 99(30) \%$, and $128(34) \%$ ) was similar to that before L-NMMA infusion $(72(28) \%$, $102(29) \%$, and $132(28) \%, p=0.84)$. The bradykinin induced reduction in coronary vascular resistance after L-NMMA (28(3)\%, $44(6) \%$, and $50(7) \%$ ) was also similar to that before L-NMMA (36(7)\%, 45(8)\%, and $55(5) \%), p=0.75)$.

ENDOTHELIUM INDEPENDENT CORONARY VASODILATATION AND CORONARY FLOW RESERVE Endothelium independent epicardial coronary vasodilatation was observed with glyceryl 
trinitrate administration in the proximal and distal coronary segments (from $3.08(0.13)$ to $3.72(0.14) \mathrm{mm}$, and from $1.41(0.04)$ to $1.80(0.07) \mathrm{mm} ; \quad \mathrm{p}<0.001, \quad$ respectively) (fig 1).
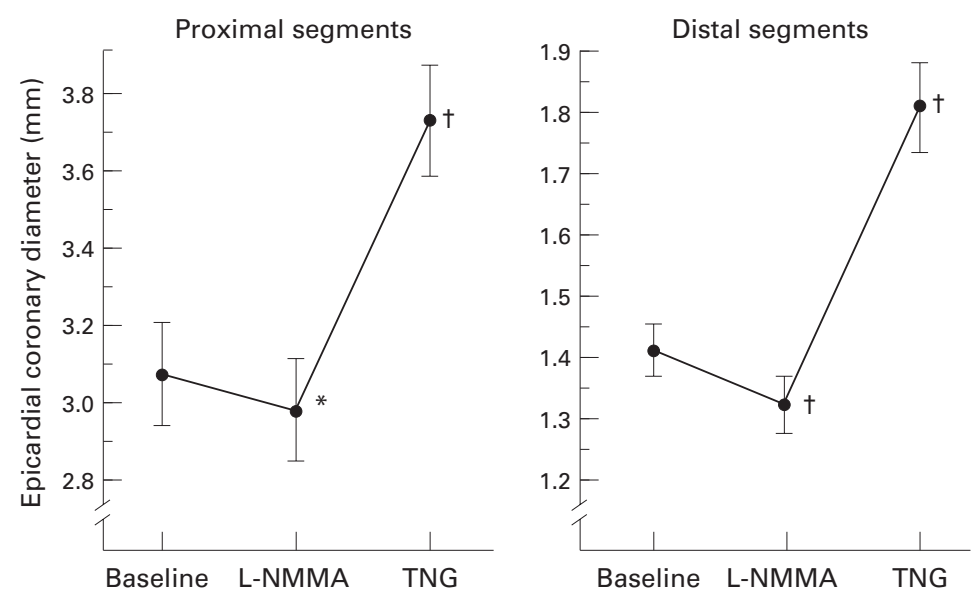

Figure 1 Epicardial coronary diameter changes with $N^{G}$-monomethyl-L-arginine (L-NMMA) and glyceryl trinitrate (TNG) in the proximal and the distal coronary segments. L-NMMA caused significant vasoconstriction in the proximal and distal segments. Glyceryl trinitrate caused significant endothelium independent vasodilatation in the proximal and distal segments. ${ }^{\star} p<0.05, \dagger p<0.001 v$ baseline.
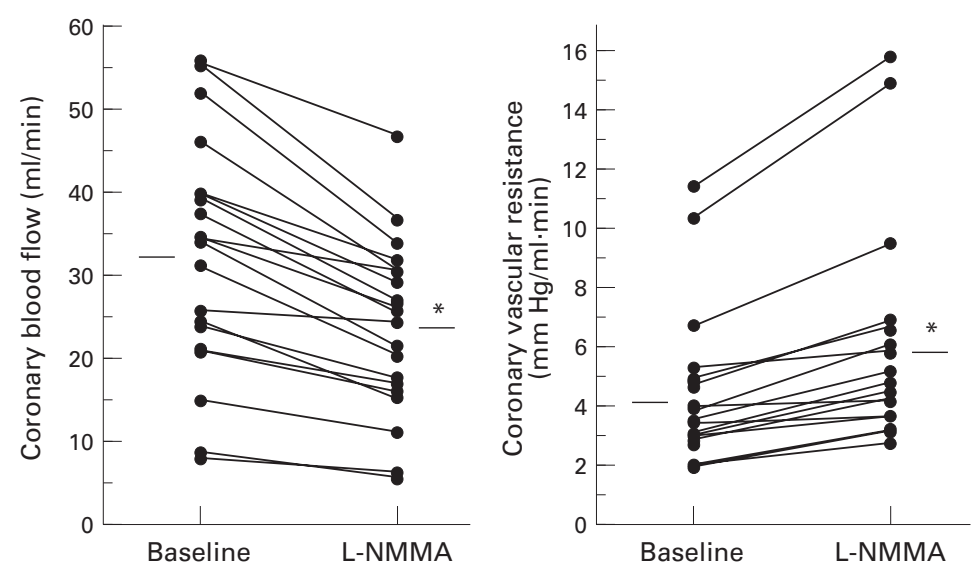

Figure 2 Coronary blood flow and coronary vascular resistance changes with $N^{G}$-monomethyl-L-arginine (L-NMMA). L-NMMA significantly decreased coronary blood flow and increased coronary vascular resistance. ${ }^{*} p<0.001 v$ baseline.
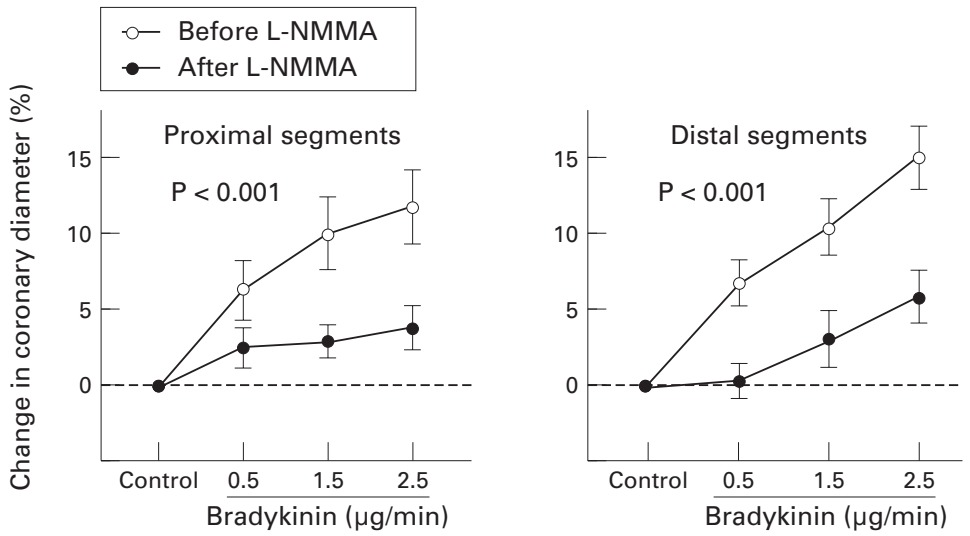

Figure 3 Percentage change in epicardial coronary diameter with bradykinin in the proximal and the distal segments before (empty circles) and after (filled circles) $N^{G}$-monomethyl-L-arginine (L-NMMA) infusion. Although bradykinin induced epicardial coronary vasodilatation in a dose dependent manner, the dilator effects were significantly attenuated after L-NMMA infusion in the proximal and distal segments $(p<0.001$ for both $)$.
Adenosine increased the coronary blood flow from $32(3)$ to $118(13) \mathrm{ml} / \mathrm{min}$ $(\mathrm{p}<0.001)$, and reduced the coronary vascular resistance from $4.2(0.6)$ to 1.1 (0.1) $\mathrm{mm} \mathrm{Hg} \cdot \mathrm{ml}^{-1} \cdot \mathrm{min}(\mathrm{p}<0.001)$. Coronary flow reserve, defined as the ratio of hyperaemic coronary blood flow in response to adenosine to resting coronary blood flow, was $>2.0$ in each patient.

\section{Discussion}

Our study confirms that L-NMMA markedly attenuates dilatation of human epicardial coronary arteries induced by exogenous bradykinin, but not the response of resistance coronary vessels. These data imply that endothelium derived nitric oxide contributes to bradykinin induced dilatation of epicardial coronary arteries, but may have less effect on coronary resistance vasodilatation.

EFFECTS OF EXOGENOUS BRADYKININ ON HUMAN EPICARDIAL CORONARY ARTERIES

Our data are consistent with previous findings that bradykinin induces human epicardial coronary vasodilatation in vivo. ${ }^{17}{ }^{18} \mathrm{~L}-\mathrm{NMMA}$ decreased basal epicardial coronary artery diameters, as previous studies have shown, ${ }^{24-26}$ providing evidence for tonic release of nitric oxide from epicardial coronary arteries under resting conditions. Furthermore, epicardial coronary vasodilatation induced by bradykinin was reduced by L-NMMA. The observed bradykinin induced dilatation of epicardial coronary arteries may partly be due to flow mediated changes, but flow change is unlikely to be primarily responsible for the reduction in bradykinin induced dilatation of the epicardial coronary arteries since the bradykinin induced increase in coronary blood flow was not affected by L-NMMA. Our finding may partially reflect inhibition of flow mediated nitric oxide release. ${ }^{27}$ However, because our previous study ${ }^{22}$ showed that mediators other than nitric oxide may be mainly responsible for the flow mediated dilatation of human epicardial coronary arteries in vivo, reduced epicardial dilatation after L-NMMA may reflect an inhibition of B2 kinin receptor mediated vascular effects. Our data suggest that not only is acetylcholine induced epicardial coronary vasodilatation mediated by endothelium derived nitric oxide in vivo-as shown by previous L-NMMA studies ${ }^{24-26}$-but also bradykinin induced coronary vasodilatation.

Slight bradykinin induced epicardial coronary vasodilatation was observed even after administration of L-NMMA. Since L-NMMA is a competitive antagonist, it is possible that the dose used in this study may have been insufficient to inhibit nitric oxide production completely. Alternatively, mediators other than nitric oxide may also contribute to the residual dilatation, EDHF for example. In support of this, previous studies ${ }^{28}{ }^{29}$ showed that the nitro-L-arginine resistant relaxations might be mediated by EDHF. Another possible contribution is increased vascular wall shear stress related to local flow velocity. ${ }^{22} 30$ 

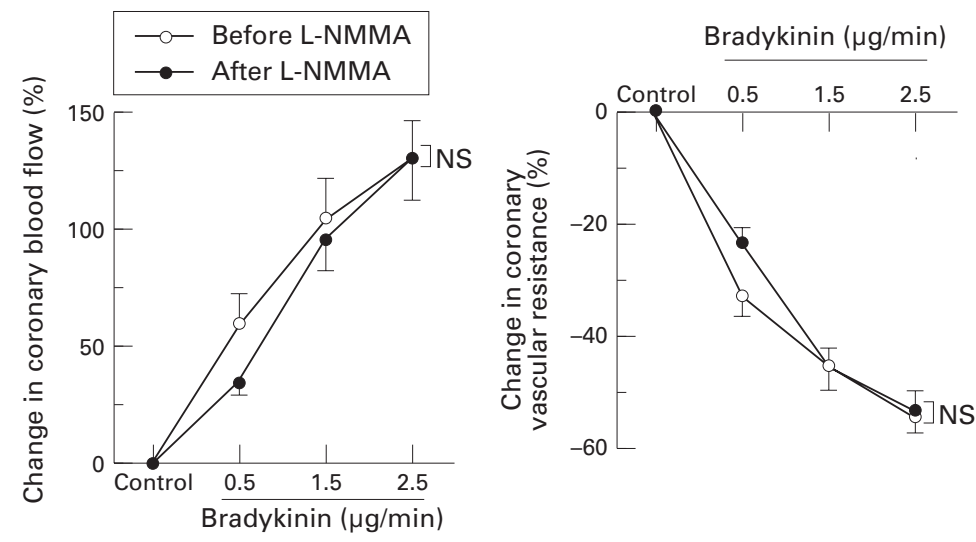

Figure 4 Percentage changes in coronary blood flow and coronary vascular resistance with bradykinin before (empty circles) and after (filled circles) $N^{G}$-monomethyl-L-arginine (L-NMMA) infusion. Bradykinin caused significant increases in coronary blood flow and decreases in coronary vascular resistance in a dose dependent manner before and after $L-N M M A$ infusion ( $p<0.001$, respectively). These effects of bradykinin on coronary blood flow and coronary vascular resistance before and after L-NMMA infusion did not differ significantly.

EFFECT OF EXOGENOUS BRADYKININ ON RESISTANCE CORONARY VESSELS

Bradykinin induces resistance coronary vasodilatation in dogs ${ }^{31} 32$ and pigs. ${ }^{33}{ }^{34}$ A previous study $^{18}$ demonstrated a role for endogenous bradykinin in normal vasomotor responses of human resistance coronary vessels in vivo by documenting the effects of HOE 140, a selective bradykinin $\mathrm{B} 2$ receptor antagonist. We investigated the effects of exogenous bradykinin on human resistance coronary vasodilatation.

L-NMMA reduced basal coronary blood flow and increased the basal coronary vascular resistance as previously shown, ${ }^{23-25}$ providing evidence for tonic release of nitric oxide from the coronary microvasculature under resting conditions. In contrast, L-NMMA did not affect the bradykinin induced increase in the coronary blood flow and reduction in the coronary vascular resistance, suggesting that bradykinin-induced resistance coronary vasodilatation is largely independent of endothelium derived nitric oxide. These results are consistent with previous studies which showed that endothelium derived relaxing agents other than nitric oxide may mediate bradykinin induced relaxation in isolated intramyocardial porcine coronary resistance arteries ${ }^{34}$ and canine coronary resistance vessels ${ }^{35}$ in vivo. Both acetylcholine induced and substance $P$ induced relaxation of coronary resistance vessels have been shown to be largely dependent on nitric oxide. ${ }^{2536}{ }^{37}$ Endothelium dependent dilatation of coronary resistance vessels may be induced by various different kinds of pharmacological probes.

STUDY LIMITATIONS

In this study, the dose of L-NMMA may have been insufficient to inhibit nitric oxide production completely. Quyyumi et al ${ }^{2526}$ gave L-NMMA at a dose of $64 \mu \mathrm{mol} / \mathrm{min}$ for five minutes, inhibiting acetylcholine induced dilatation of coronary resistance vessels. We determined the L-NMMA dose with reference to their results. However, because repeated prolonged infusions of L-NMMA at higher doses increased systemic blood pressure in previous studies, ${ }^{25} 26$ and because these high doses may induce vasoconstriction in other vascular beds, we elected not to give such high doses of L-NMMA and used only one dose.

Some of our patients had risk factors for coronary atherosclerosis which may have affected coronary endothelial function, including nitric oxide production. However, the bradykinin induced changes in coronary blood flow and coronary vascular resistance after L-NMMA infusion were similar to those before the infusion, even in patients without atherosclerotic risk factors. Therefore it is unlikely that these coronary risk factors were responsible for the minor role of nitric oxide in bradykinin induced coronary resistance vessel dilatation.

CONCLUSIONS

Exogenous bradykinin dilates both epicardial coronary arteries and resistance coronary vessels in vivo. Endothelium derived nitric oxide was found to contribute to the dilatation of the epicardial coronary arteries, though its role may be less significant in bradykinin induced coronary resistance vessel dilatation. Further basic and clinical research is needed to clarify the mechanisms for the vasodilator effects of bradykinin, especially in coronary resistance vessels.

We thank Akito Hiraoka MD, Yuji Muraoka MD, Hiroki Teragawa MD, Tadakatsu Yamada MD, and Hidekazu Hirao MD for their technical assistance and helpful comments. We also thank Miss Yuko Omura for her secretarial assistance. We gratefully acknowledge the assistance of the nurses and the technicians of the catheterisation laboratory in Hiroshima University Hospital.

1 Furchgott RF, Zawadzki JV. The obligatory role of endothelial cells in the relaxation of arterial smooth muscle by acetylcholine. Nature 1980;288:373-6.

2 Furchgott RF. Role of endothelium in responses of vascular smooth muscle. Circ Res 1983;53:557-73.

3 Bassenge E, Busse R. Endothelial modulation of coronary tone. Prog Cardiovasc Dis 1988;30:349-80.

4 Luscher TF, Richard V, Tschudi M, Yang Z, Boulanger C. Endothelial control of vascular tone in large and small coronary arteries. I Am Coll Cardiol 1990;15:519-27.

5 Moncada S, Vane JR. Pharmacology and endogenous roles of prostaglandins, endoperoxides, thromboxane A2 and prostacyclin. Pharmacol Rev 1979;30:293-331.

6 Shimokawa H, Flavahan NA, Lorenz RR, Vanhoutte PM. Prostacyclin releases endothelium-derived relaxing factor and potentiates its action in porcine coronary artery. $\mathrm{Br} \mathcal{F}$ Pharmacol 1988;95:1197-203.

7 Nakashima M, Mombouli J-V, Taylor AA, Vanhoutte PM. Endothelium-dependent hyperpolarization caused by bradykinin in human coronary arteries. F Clin Invest 1993; 92:2867-71.

8 Komori K, Lorenz RR, Vanhoutte PM. Nitric oxide, ACh, and electrical and mechanical properties of canine arterial smooth muscle. Am f Physiol 1988;255:H207-12.

9 Boulanger CM, Hendrickson H. Lorenz RR, Vanhoutte PM. Release of different relaxing factors by cultured porcine endothelial cells. Circ Res 1989;64:1070-8.

10 Nagao T, Vanhoutte PM. Hyperpolarization contributes to endothelium-dependent relaxations to acetylcholine in femoral veins of rats. Am f Physiol 1994;261:H1034-7.

11 Palmer RMJ, Ferrige AG, Moncada S. Nitric oxide release accounts for the biochemical activity of endotheliumderived relaxing factor. Nature 1987;327:524-6.

12 Hutchinson PJA, Palmer RMJ, Moncada S. Comparative pharmacology of EDRF and nitric oxide on vascular strips. Eur f Pharmacol 1987;141:445-51.

13 Moncada S, Radomski MW, Palmer RMJ. Endotheliumderived relaxing factor: identification as nitric oxide and role in the control of vascular tone and platelet function. Biochem Pharmacol 1988;37:2495-501.

14 Cherry P, Furchgott RF, Zawadzki JV, Jothianandan D. Role of endothelial cells in relaxation of isolated arteries by
bradykinin. Proc Natl Acad Sci USA 1982;79:2106-10.

15 Gilligan DM, Guetta V, Panza JA, Garcia CE, Quyyumi AA, Gilligan DM, Guetta V, Panza JA, Garcia CE, Quyyumi AA,
Cannon RO. Selective loss of microvascular endothelial Cannon RO. Selective loss of microvascular endothelial
function in human hypercholesterolemia. Circulation 1994; 90:35-41. 
16 Panza JA, Garcia CE, Kilcoyne CM, Quyyumi AA, Cannon RO. Impaired endothelium-dependent vasodilation in patients with essential hypertension: evidence that nitric oxide abnormality is not localized to a single

17 Kuga T, Egashira K, Mohri M, Tsutsui H, Harasawa Y Urabe Y, et al. Bradykinin-induced vasodilation is impaired at the atherosclerotic site but is preserved at the spastic site of human coronary arteries in vivo. Circulation 1995;92 183-9.

18 Groves P, Kurz S, Just H, Drexler H. Role of endogenous bradykinin in human coronary vasomotor control. Circulation 1995;92:3424-30.

19 Rees DD, Palmer RMJ, Hodson HF, Moncada S. A specific inhibitor of nitric oxide formation from L-arginine attenuates endothelium-dependent relaxation. $\mathrm{Br} \mathcal{F}$ Pharmacol 1989;96:418-24.

20 Ofili E, Kern MJ, Tatineni S, Deligonul U, Aguirre F, Serota $\mathrm{H}$, et al. Detection of coronary collateral flow by a Doppler-tipped guide wire during coronary angioplasty. Am Heart ₹ 1991;122:221-5.

21 Doucette JW, Corl PD, Payne HM, Flynn AK, Goto M Nassi $M$, et al. Validation of a Doppler guide wire for intravascular measurement of corona culation

22 Shiode N, Morishima N, Nakayama K, Yamagata T, Matsuura $\mathrm{H}$, Kajiyama G. Flow-mediated vasodilation of human epicardial coronary arteries: effect of inhibition of nitric oxide synthesis. F Am Coll Cardiol 1996;27:304-10.

23 Reiber JHC, Serruys PW, Kooijman CJ, Wijns W, Slager CJ, Gerbrands JJ, et al. Assessment of short-, medium-, and long-term variations in arterial dimensions from computer assisted quantitation of coronary cineangiograms. Circulation 1985;71:280-8.

24 Lefroy DC, Crake T. Uren NG, Davies GJ, Maseri A. Effect of inhibition of nitric oxide synthesis on epicardial coronary artery caliber and coronary blood flow in humans. Circulation 1993;88:43-54

25 Quyyumi AA, Dakak N, Andrews NP, Husain S, Arora S, Quyyumi AA, Dakak N, Andrews NP, Husain S, Arora S,
Gilligan DM, et al. Nitric oxide activity in the human Gilligan DM, et al. Nitric oxide activity in the human coronary circulation: impact of risk factors

26 Quyyumi AA, Dakak N, Andrews NP, Gilligan DM, Panza JA, Cannon RO. Contribution of nitric oxide to metabolic coronary vasodilation in the human heart. Circulation 1995;92:320-6.
27 Lieberman EH, Knab ST, Creager MA. Nitric oxide mediates the vasodilator response to flow in humans [abstract]. Circulation 1994;90:I-138.

28 Mombouli J-V, Illiano S, Nagao T, Scott-Burden $\mathrm{T}$, Vanhoutte PM. Potentiation of endothelium-dependent relaxations to bradykinin by angiotensin I converting enzyme inhibitors in canine coronary artery involves both endothelium-derived relaxing and hyperpolarizing factors. Circ Res 1992;71:137-44.

29 Nagao T, Vanhoutte PM. Hyperpolarization as a mechanism for endothelium-dependent relaxations in the porcine coronary artery. F Physiol (Lond) 1992;445:35567.

30 Kamiya A, Togawa T. Adaptive regulation of wall shear stress to flow change in the canine carotid artery. $A m \mathcal{F}$ Physiol 1980;239:H14-21.

31 Zanzinger J, Zheng X, Bassenge E. Endothelium dependent vasomotor responses to endogenous agonists are potentiated following ACE inhibition by a bradykinin dependent mechanism. Cardiovasc Res 1994;28:209-14.

32 Pelc LR, Gross GJ, Warltier DC. Mechanism of coronary vasodilation produced by bradykinin. Circulation 1991;83 2048-56.

33 Dube S, Rajagopalan S, Canty JM. Nitric oxide independent relaxations to bradykinin are not inhibited by calmoduin antagonists in isolated porcine coronary resistance arterioles [abstract]. Circulation 1994;90:I-256.

34 Tschudi M, Richard V, Buhler FR, Luscher TF. Importance of endothelium-derived nitric oxide in porcine coronary resistance arteries. Am f Physiol 1991;260:H13-20.

35 Sudhir K, Chou TM, Hutchinson SJ, Chatterjee K. Coronary vasodilation induced by angiotensin-converting enzyme inhibition in vivo: differential contribution of nitric oxide and bradykinin in conductance and resistance arteries. Circulation 1996;93:1734-9.

36 Egashira K, Katsuda Y, Mohri M, Kuga T, Tagawa T, Kubota T, et al. Role of endothelium-derived nitric oxide in coronary vasodilation induced by pacing tachycardia in humans. Circ Res 1996;79:331-5.

37 Quyyumi AA, Mulcahy D, Andrews NP, Husain S, Panza JA, Cannon RO. Coronary vascular nitric oxide activity in hypertension and hypercholesterolemia: comparison of acetylcholine and substance P. Circulation 1997;95:104-10. 